\title{
Phylogeography of Nasutitermes corniger (Isoptera: Termitidae) in the Neotropical Region
}

\author{
Amanda de Faria Santos ${ }^{1,2^{*}}$, Tiago Fernandes Carrijo ${ }^{3}$, Eliana Marques Cancello ${ }^{4}$ \\ and Adriana Coletto Morales-Corrêa e Castro ${ }^{1,2}$
}

\begin{abstract}
Background: The Neotropical Region is known for its biodiversity and ranks third in number of known termite species. However, biogeographic and phylogeographic information of termites of this region is limited compared to other world geographic regions. Nasutitermes corniger is widely distributed in the region and is of considerable economic importance. The goal of this study was to describe the phylogeography of $\mathrm{N}$. corniger in the Neotropical Region, to better understand its evolutionary processes.

Results: The sampled populations of $\mathrm{N}$. corniger showed high genetic variation. Results indicated strong geographic structure among N. corniger populations, with most haplotypes not broadly shared among separated locations. Phylogeographic analyses showed a dispersal route for N. corniger from Central America into South America via the Isthmus of Panama, with subsequent dispersal through the highlands east of the Andes and into eastern regions of the continent. The majority of haplotypes were limited in distribution to proximal regions, corresponding to particular biomes (Atlantic Forest, Amazonia, Chaco, Cerrado and Caatinga).
\end{abstract}

Conclusions: Nasutitermes corniger is suggested to be a good model for biogeographic and phylogeographic studies in the Neotropical Region. This study clarified the phylogeographic history of N. corniger and can contribute to the understanding of biogeographic dispersion processes in the Neotropical Region.

Keywords: Termite, Population genetics, Mitochondrial gene, $16 \mathrm{~S}$ rRNA, Biogeography, Dispersal route

\section{Background}

The American tropics is known for its biodiversity, arising from its heterogeneity of habitats, hybrid biogeographic formation, and complex geological history, factors that influence the geographic distribution of species [1].

Research confirms faunal exchange between the Americas. South America, isolated from the beginning of the Tertiary, was reconnected to the northern continent through the elevation of the Isthmus of Panama during the Pliocene, allowing continental species dispersion. Research suggests

\footnotetext{
* Correspondence: amandafasan@gmail.com

'Instituto de Biociências, Letras e Ciências Exatas, Universidade Estadual Paulista "Júlio de Mesquita Filho" (UNESP), Cristóvão Colombo Street, 2265 Jardim Nazareth, São José do Rio Preto, SP 15054-000, Brazil

¿2aboratório de Biologia Evolutiva, Faculdade de Ciências Agrárias e

Veterinárias, Universidade Estadual Paulista "Júlio de Mesquita Filho" (UNESP), Prof. Paulo Donato Castellane Access Way - Vila Industrial, Jaboticabal, SP 14884-900, Brazil

Full list of author information is available at the end of the article
}

dispersion of Neotropical biota from South America towards the north [2-6]. Two cenocrons - sets of taxa that share a biogeographic history - have been recognized: the "Old Southern" or "Ancient Neotropical" that dispersed from South to North America during the Cretaceous and Paleocene, and the more recent dispersal after the Isthmus of Panama was formed during the Pliocene and the Pleistocene, 3.5 to 4.6 million years ago (Ma) [1].

The Neotropical Region ranks third in number of known termite species, with more than 650 described species [7]. Biogeographic and phylogeographic information of termites of this region is limited compared to other world geographic regions. For example, many studies have been conducted of termite phylogeography in the Neartic Region, mainly of Reticulitermes [8-11], as well as of European [12-14], Asian [15, 16], and Australian [17] species. 
Nasutitermes corniger (Isoptera: Termitidae: Nasutitermitinae) is the most widely distributed species of Nasutitermes in the Neotropical Region. As a successful invasive termite, it has considerable economic impact [18]. Studies of its ecology [19], social behavior [20, 21], and taxonomy $[22,23]$ have been conducted.

The main goal of this study was to gain information on the phylogeography of termites in the Neotropical Region by investigating and describing genetic variation in Nasutitermes corniger. A further goal was to analyze how this variation was structured and distributed over the area of the species occurrence and how it reflects the evolution of $N$. corniger.

Mitochondrial DNA (mtDNA) was used due to its characteristics of maternal inheritance, rapid evolutionary rate, and high intraspecific polymorphism [24]. We used the 16S rRNA mitochondrial molecular marker, which, despite being more conserved than other mitochondrial genes, revealed representative genetic variations and consistently showed genetic differences among populations in previous tests.

\section{Methods}

\section{Samples and laboratory procedures}

The study used 230 soldiers (to facilitate accurate species identification) of $N$. corniger, collected throughout its distribution area (Additional file 1). Collections of samples were performed with permission issued by Instituto Chico Mendes de Conservação da Biodiversidade - ICMBio, agency responsible for environmental studies in Brazil (permission number 40673-8). Specimens were stored in $100 \%$ ethanol at the Isoptera collection of Museu de Zoologia da Universidade de São Paulo, Brazil. Total DNA was extracted from the head of one soldier per colony using the phenol-chloroform method [25]. For partial amplification of mitochondrial gene 16S rRNA, we used the oligonucleotides $L R-J-13007$ [26] and $L R-N-1398$ [27] in a PCR reaction in a final volume of $25 \mu \mathrm{L}$ comprising $3 \mu \mathrm{L}$ of each oligonucleotide at $5 \mathrm{pmol} / \mu \mathrm{L}, 4 \mu \mathrm{L}$ of deionized water, $12.5 \mu \mathrm{L}$ of PCR Master Mix (Promega), and $2.5 \mu \mathrm{L}$ of DNA, mean concentration $15 \mathrm{ng} / \mu \mathrm{L}$. This reaction was submitted to amplification under the following conditions: initial denaturation at $94{ }^{\circ} \mathrm{C}$ for 2 min followed by 35 cycles of denaturation for $1 \mathrm{~min}$ at $94{ }^{\circ} \mathrm{C}$, annealing of $1 \mathrm{~min}$ at $50{ }^{\circ} \mathrm{C}$, and extension of $75 \mathrm{~s}$ at $72{ }^{\circ} \mathrm{C}$, followed by a final extension at $72{ }^{\circ} \mathrm{C}$ for $7 \mathrm{~min}$ [28]. The PCR product was treated with the NucleoSpin ${ }^{\circ}$ Gel and PCR Clean-up kit (Macherey-Nagel) following manufacturer's instructions. The DNA samples were sequenced by the BigDye reagent kit (Perkin-Elmer) in an automatic sequencer ABI 3730 XL DNA Analyzer (Applied Biosystems), according to manufacturer's instructions. The sequencing reaction was submitted to the same amplification reaction conditions as the mitochondrial gene fragment.

\section{Data analysis}

The nucleotide sequences were read using Chromas Lite v. 2.01 (Technelysium Ltd., 2005). We aligned the sequences using the ClustalW tool in BioEdit v.7.0.9.0 [29], followed by visual inspection, and conducted descriptive statistics analyses in DnaSP v.5.10.01 [30]. To quantify the variation in the mtDNA sequences, the following parameters were estimated: number of polymorphic or segregating sites (S), nucleotide diversity $(\pi)$, average number of nucleotide differences $(\mathrm{k})$, and haplotype diversity (Hd). Using MEGA v.6 [31], we estimated the mean percentage of each base in the composition of the mtDNA sequences.

We performed Fu's Fs [32] and Tajima's D [33] neutrality tests with DnaSP v.5.10.01 [30]. Significant negative values for Fu's Fs are indicative of population expansion [32]. Significant negative values for Tajima's D suggest purifying selection, lift effect, or population expansion. Positive values indicate stabilizing selection or population contraction [33].

We also used DnaSP v.5.10.01 to calculate mismatch distribution. This analysis allows discrimination among populations that remained stable over time (multimodal curves) and populations that underwent demographic expansion from a small founding population (unimodal curves) [34-37].

For the phylogeographic analysis, we performed the nested clade phylogeographic analysis (NCPA) from a haplotype network obtained using the software TCS v.1.21 [38], nested manually according to the method proposed by Templeton [39]. Using GeoDis v.2.5 [40], we calculated clade distance (Dc), nested clade distance (Dn), and interior-tip (I-T) for the clades formed in the haplotypic network. The parameters calculated and their significance were tested in the phylogeographic inferences key of Templeton [41]. For verification of results, we conducted the Mantel test using Alleles in Space v.1.0 [42]. Significant $r$ values nearest to 1 indicate strong positive correlation between the two variables. Significant values nearest to -1 indicate strong negative correlation between the variables. Values of zero denote no linear correlation between the matrices.

We conducted the analyzes of molecular variance (AMOVA) using Arlequin v.3.11 [43], including all haplogroups observed in the haplotypic network.

For estimating divergence time, we conducted a Bayesian inference analysis of the obtained haplotypes. This analysis was generated through the program BEAST 1.8.0 [44] using the lognormal relaxed molecular clock. We used three calibration points through the dating of fossil records: a point at 
Nasutitermes including the haplotypes of $N$. corniger and a sequence of $N$. guayanae, dated to $18 \mathrm{Ma}$ [45]; a point at Nasutitermitinae including the group Nasutitermes and a sequence of Mironasutitermes shangchengensis, dated to $30 \mathrm{Ma}$ [46]; and a point at Termitidae including the group Nasutitermitinae and two sequences of Spinitermes species that was dated at $55 \mathrm{Ma}[45,47]$. The best nucleotide substitution model found for this analysis was $\mathrm{HKY}+\mathrm{G}+\mathrm{I}$ [48], selected by MEGA v.6 [31] and based on the Bayesian Information Criterion [49].

\section{Results}

\section{Descriptive statistics}

After alignment and visual inspection, we obtained 230 (401 bp) partial sequences of the $16 \mathrm{~S}$ rRNA gene of $N$. corniger. Among the sequences, we found 33 polymorphic sites and 45 haplotypes with high haplotype diversity ( $\mathrm{Hd}$ $=0.880$ ). Nucleotide diversity was 0.00505 and the mean number of nucleotide differences was 1.988 . The mean nucleotide composition of the sequences was $25.2 \%$ thymine (T), $21.1 \%$ cytosine (C), $42.7 \%$ adenine (A), and $11 \%$ guanine $(G)$. These data showed high genetic variation among populations. The percentage of $\mathrm{A} / \mathrm{T}$ bases was higher than the percentage of $\mathrm{C} / \mathrm{G}$ bases, as is expected for insect mitochondrial genomes.

\section{Haplotypic network and phylogeographic analyses}

To observe the relationship among haplotypes, we generated a network using all analyzed sequences. The network (Fig. 1) grouped all specimens of $N$. corniger according to haplotype (Additional file 2), showing the proximity among them based on the number of mutational steps. We defined six large haplogroups in the network, distributed throughout the Neotropical Region. To establish the haplogroups, we observed the presence of frequent haplotypes positioned more centrally in their respective haplogroup, which gave rise to less frequent derived haplotypes positioned peripherally. This type of relationship among haplotypes produces a star-shaped structure, with several derived haplotypes around a central haplotype.

For the phylogeographic analyses among populations, we considered 19 clades in the NCPA (Additional file 3). Eleven clades showed significant results, including levels three and four (Table 1). Interpretation of the NCPA results using the Templeton Inference Key [41] frequently indicated "restricted gene flow with isolation-bydistance" as the source of the observed haplotype distribution pattern.

\section{Mantel test}

The Mantel test was used to confirm the results of the NCPA. The test resulted in a significant positive $R$ value

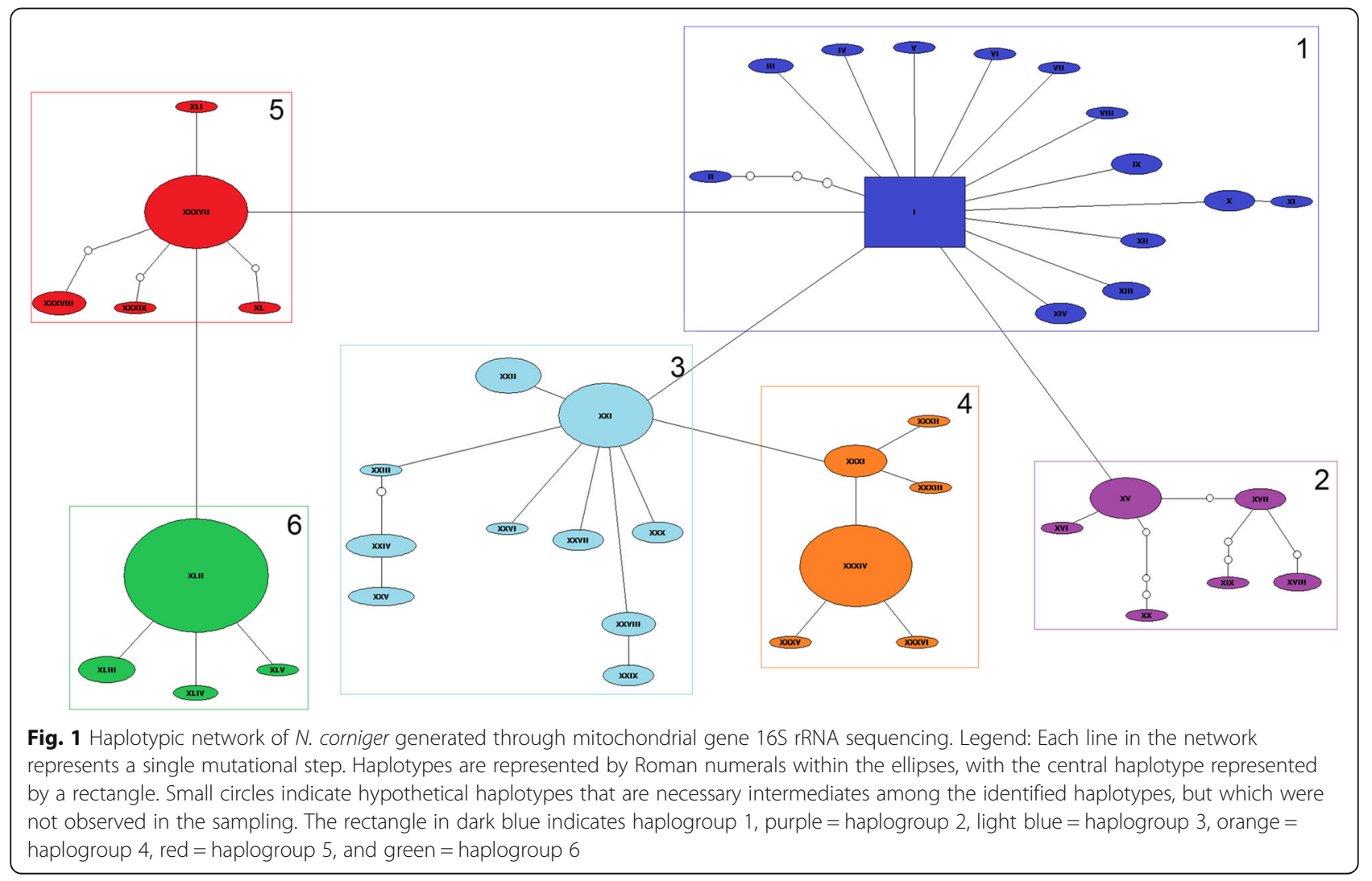


Table 1 Phylogeographic analysis of N. corniger based on NCPA and interpreted using the Templeton Inference Key [41]

\begin{tabular}{|c|c|c|c|c|}
\hline Clade & Significant subset & Significant parameters & Significant I-T parameters & Phylogeographic inference \\
\hline \multirow[t]{3}{*}{$1-1$} & I (interior) & $D c>; D n>$ & \multirow[t]{3}{*}{$D c>; D n>$} & \multirow[t]{3}{*}{ Restricted gene flow with isolation by distance } \\
\hline & IX (tip) & Dc $<$ & & \\
\hline & XIV (tip) & $\mathrm{Dc}<$ & & \\
\hline \multirow[t]{3}{*}{$1-9$} & XXII (tip) & Dc< & \multirow[t]{3}{*}{ Dc> } & \multirow[t]{3}{*}{ Restricted gene flow with isolation by distance } \\
\hline & XXVII (tip) & $\mathrm{Dc}<$ & & \\
\hline & XXX (tip) & Dc< & & \\
\hline $1-19$ & XLIII (tip) & $\mathrm{Dc}<$ & None & Restricted gene flow with isolation by distance \\
\hline \multirow[t]{2}{*}{$2-1$} & $1-1$ (interior) & $D c>; D n>$ & \multirow[t]{2}{*}{$D c>; D n>$} & \multirow[t]{2}{*}{ Restricted gene flow with isolation by distance } \\
\hline & 1-3 (tip) & $\mathrm{Dc}<; \mathrm{Dn}<$ & & \\
\hline $2-5$ & $1-12$ (tip) & Dc< & Dc> & Restricted gene flow with isolation by distance \\
\hline \multirow[t]{2}{*}{$2-7$} & $1-13$ (interior) & $D c>; D n>$ & \multirow[t]{2}{*}{$D c>; D n>$} & \multirow[t]{2}{*}{ Restricted gene flow with isolation by distance } \\
\hline & $1-14$ (tip) & $\mathrm{Dc}<; \mathrm{Dn}<$ & & \\
\hline $2-8$ & $1-19$ (tip) & $\mathrm{Dc}<; \mathrm{Dn}<$ & $D c>; D n>$ & Restricted gene flow with isolation by distance \\
\hline \multirow[t]{2}{*}{$3-1$} & 2-1 (interior) & Dc $<$ & \multirow[t]{2}{*}{ Dc> } & \multirow[t]{2}{*}{ Restricted gene flow with isolation by distance } \\
\hline & 2-8 (tip) & Dc $<$ & & \\
\hline $3-2$ & 2-4 (tip) & $\mathrm{Dn}<$ & $\mathrm{Dn}>$ & Restricted gene flow with isolation by distance \\
\hline $3-3$ & 2-7 (tip) & $\mathrm{Dc}<$ & None & Restricted gene flow with isolation by distance \\
\hline \multirow[t]{2}{*}{$4-1$} & $3-2$ (tip) & $D c<; D n>$ & \multirow[t]{2}{*}{$D c>; D n>$} & \multirow{2}{*}{$\begin{array}{l}\text { Restricted gene flow or Dispersion with some } \\
\text { long-distance dispersion }\end{array}$} \\
\hline & 3-3 (tip) & $\mathrm{Dc}<; \mathrm{Dn}<$ & & \\
\hline
\end{tabular}

Dc clade distance, Dn nested clade distance, $I-T$ interior-tip

(0.252090, $p=0.0009)$, indicating correlation between haplotype genetic distance and geographic distance, that is the number of differences observed among haplotypes from proximal localities was lower than among haplotypes from more widely separated sites.

\section{Neutrality tests and mismatch distribution}

Neutrality tests and mismatch distribution analysis were performed to investigate the demographic history of the sampled populations. Initially, all $N$. corniger specimens were treated as a single group in the neutrality tests. The obtained Fu's Fs and Tajima's D values were significantly negative $(-31.673 ; p<0.05$ and $-3.3115 ; \mathrm{p}<0.05$, respectively), indicating population expansion. Neutrality tests were also conducted separately for each of the six haplogroups (Table 2). All tests produced significant negative values of Fu's Fs, again consistent with population expansion. Tajima's D test produced a significant negative value only for haplogroup $1(-1.96222 ; p<0.05)$.

We also analyzed mismatch distribution of all sequences of $N$. corniger as a single group well as of each haplogroup separately. The obtained graph showed unimodal curves, indicating that the populations may have undergone recent expansion (Fig. 2).

\section{Analysis of molecular variance (AMOVA)}

An AMOVA was performed to evaluate the degree of genetic variation among $N$. corniger haplogroups. We tested two hierarchy constructions, the first including all haplogroups within a single larger group. The results of this analysis were significant $(p<0.05)$ and showed high genetic differentiation within and among the haplogroups (Table 3). The $\mathrm{F}_{\mathrm{ST}}$ value indicated a high degree of genetic structure among the haplogroups.

In the second construction, we segregated the haplogroups according to geographic location to evaluate the degree of structure of haplogroups with restricted distribution. Haplogroup 1 was omitted from the analysis due to its broad distribution (Fig. 3). We constructed three larger groups, the first containing all sequences present in Haplogroup 2 (almost exclusively Central America), the second comprising sequences present in Haplogroups 3 and 4

Table 2 Neutrality tests (DnaSP v.5). N. corniger specimens analyzed as a single group and with each haplogroup in the haplotype network analyzed separately (Fig. 1)

\begin{tabular}{lll}
\hline Samples considered & Fu's Fs & Tajima's D \\
\hline All & $-31.673^{*}$ & $-3.3115^{*}$ \\
Haplogroup 1 & $-9.162^{*}$ & $-1.96222^{*}$ \\
Haplogroup 2 & $-1.282^{*}$ & -1.71862 \\
Haplogroup 3 & $-2.787^{*}$ & -0.37922 \\
Haplogroup 4 & $-0.986^{*}$ & -0.63467 \\
Haplogroup 5 & $-0.883^{*}$ & -1.43621 \\
Haplogroup 6 & $-1.691^{*}$ & -1.02028 \\
\hline
\end{tabular}

*Significant values $(p<0.05)$ 

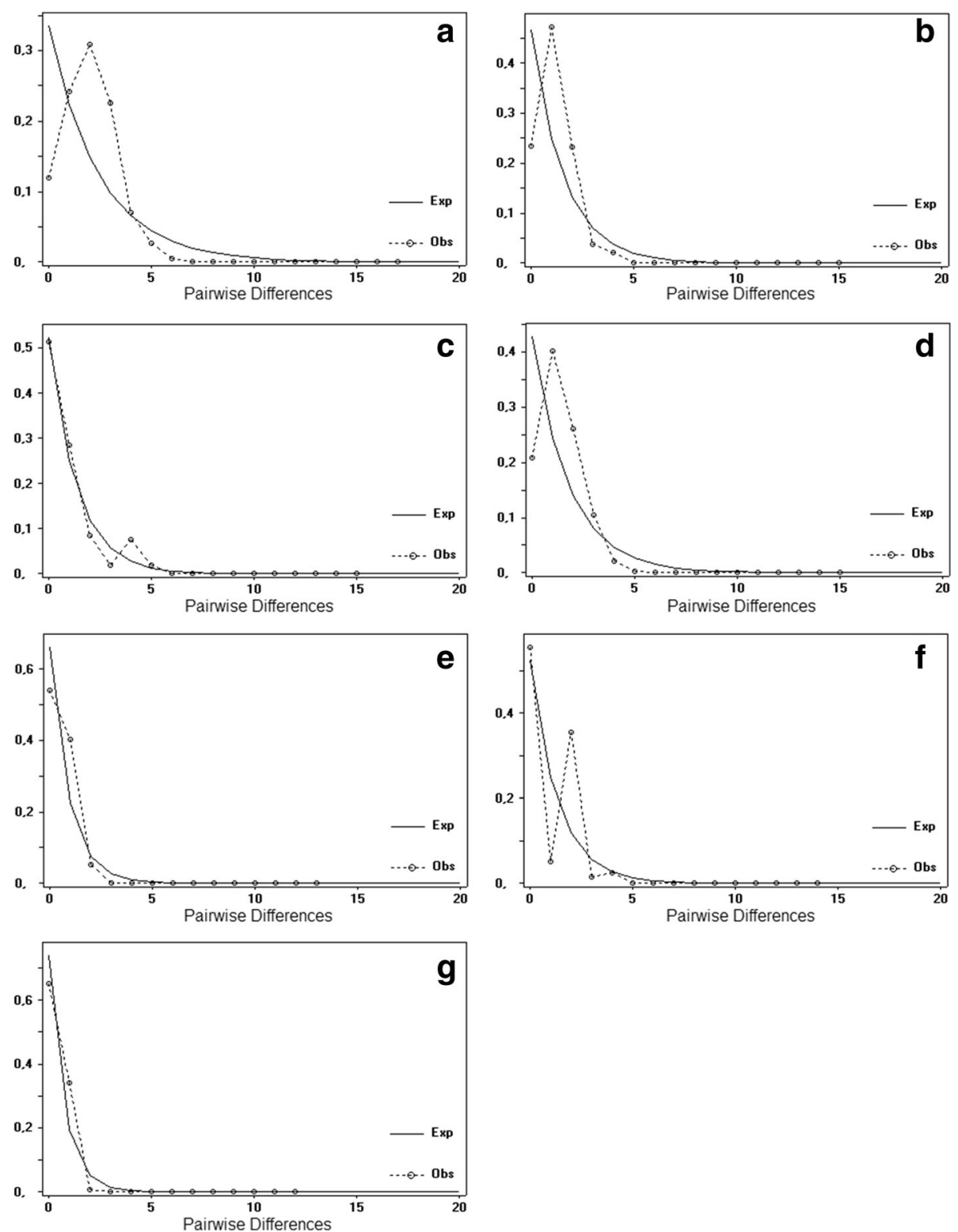

Fig. 2 Pairwise difference mismatch distribution of the 165 rRNA sequences. Legend: Graph generated a for all N. corniger sampled populations; b-g for Haplogroups 1, 2, 3, 4, 5, and 6, respectively

(predominantly west-central South America), and the third containing the sequences of Haplogroups 5 and 6 (predominantly east-central South America). All results were significant $(p<0.05)$ and indicated population structure as shown by high $\mathrm{F}$ indices for the established groups (Table 4). The

Table 3 AMOVA assessment of genetic variation among $N$. corniger considering all haplogroups as a single group

\begin{tabular}{llll}
\hline Source of variation & $\begin{array}{l}\text { Variance } \\
\text { components }\end{array}$ & Variation \% & Fixation index \\
\hline Among haplogroups & 0.99576 & 65.46 & $\mathrm{~F}_{\mathrm{ST}}=0.65457^{*}$ \\
Within haplogroups & 0.52547 & 34.54 & - \\
\hline
\end{tabular}

*Significant value $(p=0.00000)$
$\mathrm{F}_{\mathrm{ST}}$ value (0.71436) indicated high genetic differentiation within haplogroups too.

\section{Analysis of divergence time}

The divergence time of the haplogroups was estimated by Bayesian analysis (Fig. 4) using the 45 haplotypes obtained in this work. The topology of the tree confirmed the haplogroups observed in the network (Fig. 1) with the exception of Haplogroup 5, the branch of which includes Haplogroup 6. The tree provided evidence of two cladogenetic events generating the $N$. corniger haplogroups identified in this study. The first event corresponded to the divergence of the lineage that gave rise to Haplogroup 2, 


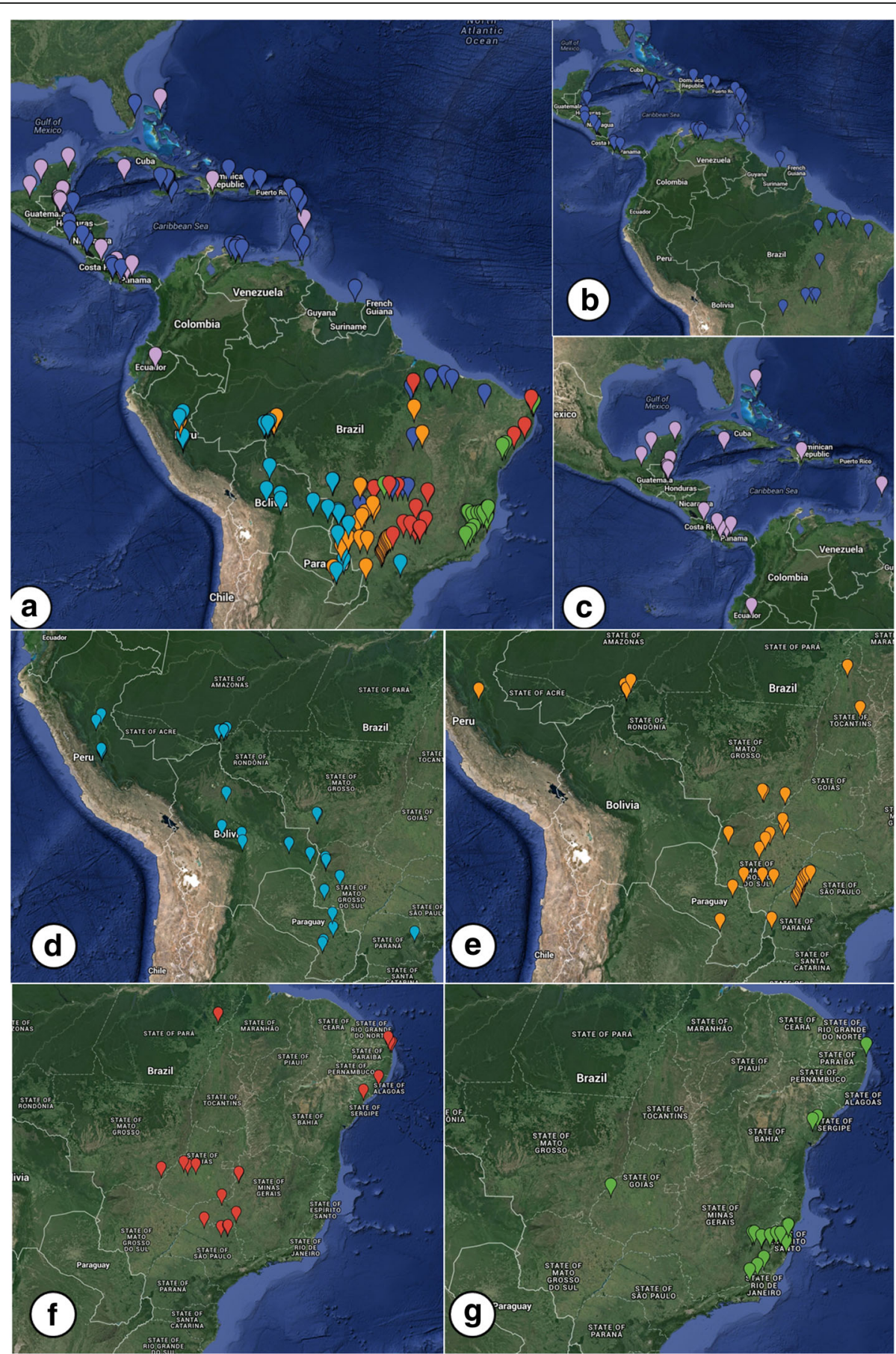

Fig. 3 Nasutitermes corniger haplotype distribution. Legend: a Haplotypes allocated to their respective locations. The colors of the point markers correspond to the colors of the haplogroups observed in the network (Fig. 1); b-g: locations corresponding to the haplogroups 1, 2, 3, 4, 5, and 6, respectively. Images generated using Google Maps

about 5.99 Ma. This was the first lineage to diverge, separate from the lineage of the five other haplogroups. The second cladogenetic event corresponded to the divergence among the lineages that gave rise to Haplogroups 1, 5, and 6, and to Haplogroups 3 and 4, about 5.1 Ma. However, although Haplogroup 2 was derived from the original lineage, its haplotypes diversified later than did those of Haplogroup 1. The diversification time for the haplotypes of Haplogroups 1 and 2 was $2.87 \mathrm{Ma}$ and $2.62 \mathrm{Ma}$, respectively. That is, although the lineage of Haplogroup 1 was established later than Haplogroup 2, its haplotypes diverged earlier than those of Haplogroup 2. The diversification time of 
Table 4 AMOVA assessment of genetic variation among the sampled N. corniger populations

\begin{tabular}{llll}
\hline Source of variation & $\begin{array}{l}\text { Variance } \\
\text { components }\end{array}$ & Variation \% & Fixation index \\
\hline Among groups & 0.57593 & 32.72 & $\mathrm{~F}_{\mathrm{CT}}=0.32721^{*}$ \\
$\begin{array}{l}\text { Among haplogroups } \\
\text { within groups }\end{array}$ & 0.68143 & 38.71 & $\mathrm{~F}_{\mathrm{SC}}=0.57544^{*}$ \\
Within haplogroups & 0.50277 & 28.56 & $\mathrm{~F}_{\mathrm{ST}}=0.71436^{*}$ \\
\hline
\end{tabular}

*Significant value $(p=0.00000)$ the branch that included Haplogroups 5 and 6 is the second oldest, at $2.77 \mathrm{Ma}$. The most recent estimated divergence time was $1.09 \mathrm{Ma}$ for Haplogroup 6. The estimated diversification times for Haplogroups 3 and 4 were $2.33 \mathrm{Ma}$ and $1.36 \mathrm{Ma}$, respectively.

\section{Discussion}

Genetic population results

The results indicated high genetic variation among the $N$. corniger sampled, as well as strong geographic structure among the populations.

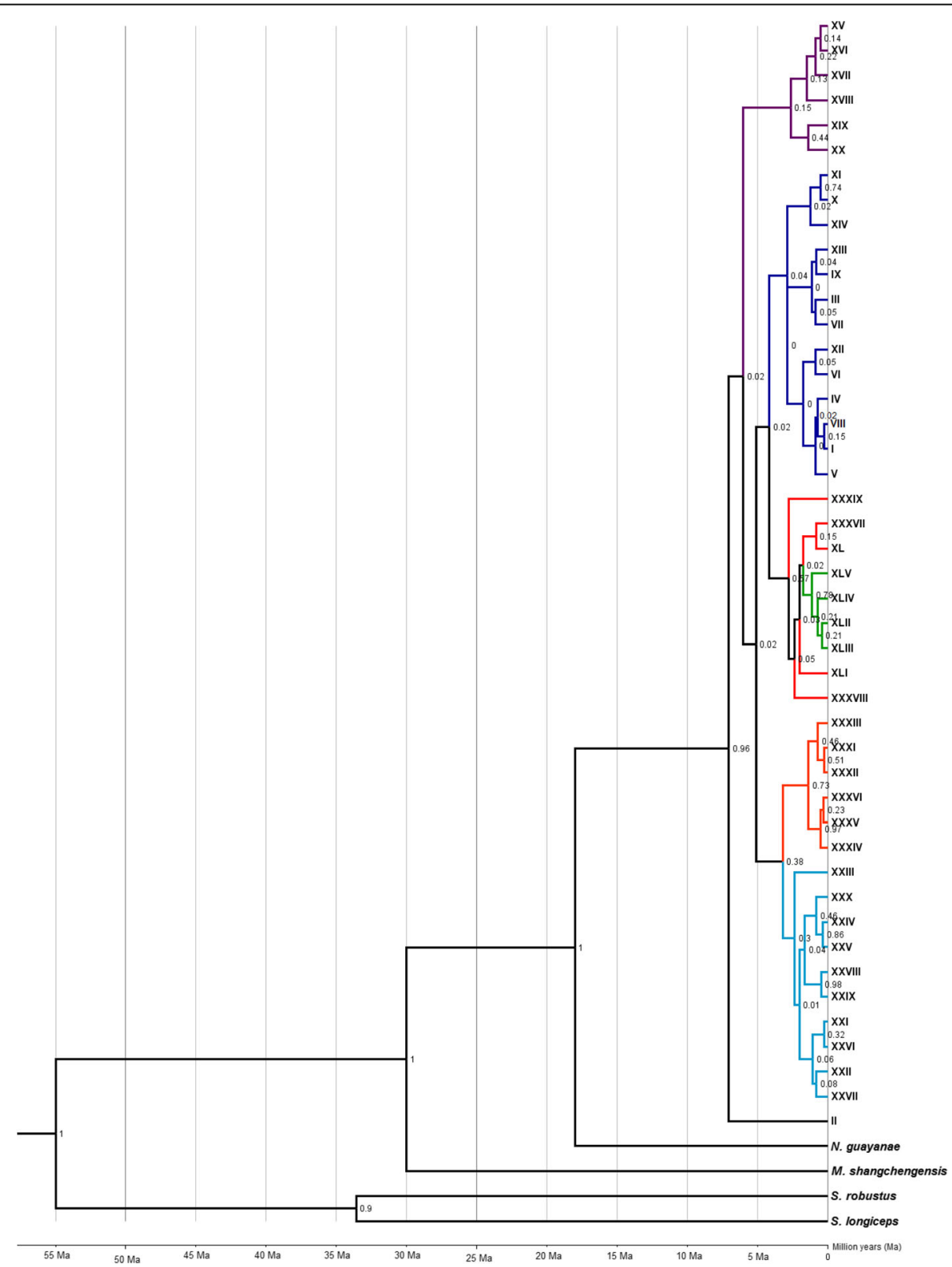

Fig. 4 Bayesian tree generated with the 45 Nasutitermes corniger haplotypes obtained. Legend: The colors of the branches correspond to the colors of the haplogroups identified in the network (Fig. 1). Numbers at the nodes of branches correspond to Bayesian posterior probabilities. The bar below the tree marks the estimated divergence time 
The variation can be confirmed by a high number of haplotypes and high haplotype diversity. The structure was demonstrated by the configuration of the haplogroups in the network, which included primarily adjacent or closely related geographic regions, except for Haplogroup 1, which was more widely distributed. This pattern of genetic structure can also be shown by the high genetic distance among the haplogroups and, chiefly, by the AMOVA results of high F values. Most of the haplotypes identified in the $N$. corniger populations were not broadly shared among specimens from widely separated geographic areas.

The observed structure pattern demonstrated that haplotypes can be associated with geographic region. In Central America and the Caribbean Islands, we found only haplotypes of Haplogroups 1 and 2 (Figs 3a-c). Haplogroup 2 is essentially exclusive to these regions. The eastern regions of the Andes were characterized by Haplogroup 3 (Fig. 3d); in southwest Brazil, Haplogroup 4 predominated (Fig. 3e); in south-central Brazil, Haplogroup 5 (Fig. 3f); and in east-southeast Brazil we observed only Haplogroup 6 (Fig. 3g).

\section{Phylogeographic and biogeographic results}

Phylogeographic analysis suggested a dispersal route of N. corniger from Central America toward South America via the Isthmus of Panama with subsequent dispersal through the highlands east of the Andes and eastern regions of the continent.

In the haplotypic network (Fig. 1), we observed that Haplotype I, included in Haplogroup 1, which occupied the central position, was common and widely distributed throughout the sampling area. The coalescence theory $[50,51]$ suggests that Haplotype I may be the most ancient haplotype. Thus, it was possible to identify a probable dispersion center for the species in Central America in which Haplotype I and others of this haplogroup are most common.

The Bayesian tree (Fig. 4) showed the diversification time of Haplogroups 1 and 2 to be close, 2.87 Ma and $2.60 \mathrm{Ma}$, respectively. Haplotypes of the two groups are found in both the continental areas and the islands of Central America. This suggests that migration of N. corniger in Central America and the Caribbean Islands occurred before the vicariance processes separating these regions. The times of these migration events are likely earlier than the diversification times of Haplogroups 1 and 2 estimated by Bayesian analysis.

The relationships of origin and descent among $N$. corniger haplotypes can be best understood via the haplotypic network, which is an appropriate method for making phylogeographic inferences. Bayesian analysis is efficient in phylogenetic analyses and accurate for the estimate of divergence and diversification times; however, it is of limited effectiveness in clarifying ancestral relations among intraspecific haplotypes [52, 53].

The haplotypic network (Fig. 1) in combination with the distribution patterns of haplotypes in the sampled regions (Fig. 3), allowed speculation of an $N$. corniger dispersion route. We assumed that the elevation of the Isthmus of Panama during Pliocene allowed dispersion of $N$. corniger toward South America. This event also allowed the exchange of many other faunistic taxa [3-6]. The diversification dates of Haplogroups 3, 4, 5, and 6, found only in South America, is later than the estimated date of complete elevation of the Isthmus of Panama, from 3.5 to $4.6 \mathrm{Ma}$, supporting the hypothesis that the event may have allowed dispersal of $N$. corniger populations to South America. A model of dispersal from North America to South America by terrestrial connection had been proposed for flies of the genera Coenosopsia (Diptera: Anthomyiidae) and Phaonantho (Diptera: Anthomyiidae) [54]. We suggest a similar pattern of dispersion for $N$. corniger, although at the specific level.

The configuration of the haplogroups in the network (Fig. 1), the distribution of the haplotypes in the sampled regions (Fig. 3), and the diversification times of haplogroups suggest the following phylogeographic movements of $N$. corniger populations in South America:

1) After entering the South American continent, the populations dispersed in a southerly direction east of the Andes, originating the haplotypes of Haplogroup 3 about 2.62 Ma ago (Fig. 5a).

2) Populations that contained haplotypes of Haplogroup 3 dispersed in an easterly direction, originating Haplogroup 4 approximately $1.36 \mathrm{Ma}$ ago, primarily in western Brazil. Some of these haplotypes reached the southwest portion of the State of São Paulo, Brazil (Fig. 5b).

3) Some haplotypes of Haplogroup 1 are found in central Brazil. It is probable that these haplotypes gave rise to Haplogroup 5, which is predominantly found in central and northeast Brazil (Fig. 5c).

4) Some haplotypes of Haplogroup 5 dispersed toward eastern Brazil, giving rise to Haplogroup 6, about $1.09 \mathrm{Ma}$ (Fig. 5d).

Other models of dispersal routes in South America through the highlands of the east of Andes have been proposed [55]. A well-supported hypothesis states that organisms disperse naturally prior to becoming geographically isolated due to geological events, resulting in vicariance, for example [56]. This can explain the patterns observed in $N$. corniger. Throughout dispersal of $N$. corniger populations, some haplotypes may have differentiated and remained relatively isolated, resulting in a pattern of population structure caused by isolation-by- 

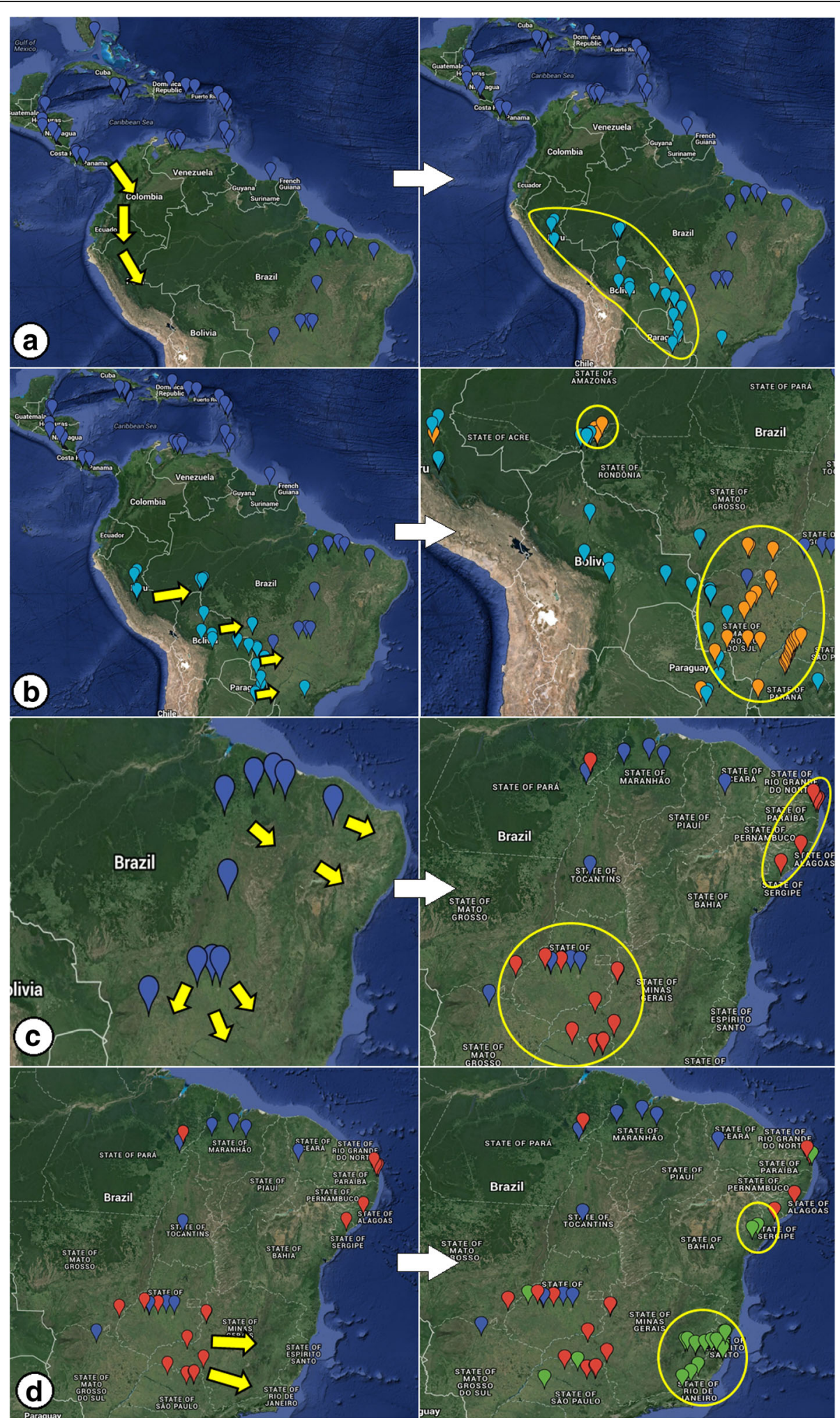

Fig. 5 Dispersion processes of Nasutitermes corniger in South America. Legend: Establishment of Haplogroups 3, 4, 5, and 6 (a to d, respectively). Arrows indicate the direction of dispersion; circles show the region in which the haplogroups predominate. Images generated using Google Maps 
distance, as supported by results of the AMOVA and NCPA.

The geographic distribution of the $N$. corniger haplogroups and the biomes found in South America show overlap of some characteristics. Haplogroup 6 is essentially exclusive to the Atlantic Forest regions of southeast and northeast Brazil, suggesting that the biogeographic processes of formation and evolution of the Atlantic biome led to its genetic structure. The expansion of the diagonal of open formations (Chaco, Cerrado, and Caatinga), for example, isolated the Atlantic Forest from other South American forests [57] and contributed to its complex biogeographic history. Many areas of endemism have been proposed in the Atlantic Forest. The definition of these areas depends of the taxa studied, the variables evaluated, and the scale of the sampling [58].

We can associate the geographic location of Haplogroup 5 to the Cerrado and Caatinga areas, typically arid biomes of Brazil. The region also includes Haplogroup 1, suggesting residual populations that maintained earlier haplotypes. The occurrence of Haplogroups 5 and 6 in northeastern Brazil can be explained by areas of transition between the Atlantic biome, where Haplogroup 6 is nearly exclusive, and the Caatinga, where we found Haplogroup 5.

We observed a predominance of Haplogroups 3 and 4 in the Chaco region. Haplogroup 3 inhabits the transition zone between the Andean region and the Neotropical sensu stricto [1] reaching the Chaco in Bolivia and Paraguay. Haplogroup 4 included an area of Amazonian biome in Rondonia State, Brazil, and also included the Chaco, reaching easterly into regions of mixed forest (Interior Atlantic Forest) in Parana, Brazil.

\section{Conclusion}

The sampled populations of $N$. corniger showed high genetic variation and structure throughout the Neotropical Region. In the haplotypic network, we observed six large haplogroups, which served as the basis for analyses of the evolutionary history of populations throughout their distribution area. From these analyses, it was possible to propose a dispersal route for the species, from Central America toward South America via the Isthmus of Panama and, subsequently, into the highlands of the eastern Andes, and eastern regions of the continent. New haplotypes were generated, many restricted to limited geographic areas corresponding to certain biomes, such as the populations found in the Atlantic Forest and in the open vegetation areas of Cerrado and Caatinga.

We suggest Nasutitermes corniger to be a good model for biogeographic and phylogeographic studies in the Neotropical Region. The use of temporal information provided by phylogenetic and phylogeographic molecular analyses, allow inference of associations between evolutionary pattern formation and a shared history of biotic diversification. This work helps to clarify the phylogeographic history of $N$. corniger, and can contribute to understanding of biogeographic dispersion processes in the Neotropical Region. We suggest that results of analysis by different models can be complementary in explaining patterns of speciation and diversity [59].

\section{Additional files}

Additional file 1: Information of the Nasutitermes corniger specimens used. Voucher number, location code, locality of origin, and geographic coordinates of the Nasutitermes corniger specimens used in this work. (DOCX $37 \mathrm{~kb}$ )

Additional file 2: Details of observed Nasutitermes corniger haplotypes. Relationship among haplotypes, their frequency, sharing with $N$. corniger specimens, and allocation to haplogroup. Letters preceding voucher numbers (final column) correspond to the respective location code. (DOCX $19 \mathrm{~kb}$ )

Additional file 3: Haplotypic network evidencing the nested clades used in the NCPA. Each line of the network represents a single mutation step. Haplotypes are represented by Roman numerals; small circles indicate hypothetical haplotypes that are necessary intermediates between the haplotypes observed. Dotted lines indicate level 1 clades; dashed lines indicate level 2 clades; full clear lines indicate level 3 clades; full dark lines indicate level 4 clade. (PDF 218 kb)

Additional file 4: Dataset used in this study. Nucleotide sequences of the specimens used in this study. (TXT $110 \mathrm{~kb}$ )

\section{Abbreviations \\ A: Adenine; AMOVA: Analysis of molecular variance; BIC: Bayesian information criterion; C: Cytosine; DNA: Deoxyribonucleic acid; G: Guanine; Ma: Millions of years; MZUSP: Museu de Zoologia da Universidade de São Paulo; \\ NCPA: Nested clade phylogeographic analysis; PCR: Polymerase chain reaction; T: Thymine; UFABC: Universidade Federal do ABC; \\ UNESP: Universidade Estadual Paulista}

\section{Acknowledgements}

We thank Prof. Dr. Rudolf Scheffrahn, University of Florida, and to the team of the Isoptera Collection of MZUSP for assistance in obtaining samples; the Laboratory of Genetic of Bacteria (FCAV/UNESP) for providing equipment; and the members of the Laboratory of Evolutionary Biology (FCAV/UNESP) for collaboration in the analyses.

Availability of data and material

The dataset used in this study is available as Additional file 4.

\section{Funding}

CAPES: scholarship to AFS; CNPq (Proc. 308,227/2013-0): award of a grant to EMC; FAPESP (Proc.13/20068-9): financial support. All these funding bodies were essential for the financing of samples collection and laboratory procedures.

\section{Authors' contributions}

AFS and ACMCC generated, analyzed, and interpreted the results. AFS, TFC, and EMC collected the specimens. All the authors contributed, read, and approved the final manuscript.

\section{Author information}

Not applicable.

Ethics approval and consent to participate Not applicable.

Consent for publication

Not applicable. 


\section{Competing interests}

The authors declare that they have no competing interests.

\section{Publisher's Note}

Springer Nature remains neutral with regard to jurisdictional claims in published maps and institutional affiliations.

\section{Author details}

'Instituto de Biociências, Letras e Ciências Exatas, Universidade Estadual Paulista "Júlio de Mesquita Filho" (UNESP), Cristóvão Colombo Street, 2265 Jardim Nazareth, São José do Rio Preto, SP 15054-000, Brazil. ${ }^{2}$ Laboratório de Biologia Evolutiva, Faculdade de Ciências Agrárias e Veterinárias, Universidade Estadual Paulista "Júlio de Mesquita Filho" (UNESP), Prof. Paulo Donato Castellane Access Way - Vila Industrial, Jaboticabal, SP 14884-900, Brazil. ${ }^{3}$ Centro de Ciências Naturais e Humanas, Universidade Federal do ABC (UFABC), Arcurus Street, 3 - Jardim Antares, São Bernardo do Campo, SP 09606-070, Brazil. ${ }^{4}$ Laboratório de Isoptera, Museu de Zoologia da Universidade de São Paulo (MZUSP), Nazaré Avenue, 481 - Ipiranga, São Paulo, SP 04263-000, Brazil.

\section{Received: 20 December 2016 Accepted: 16 November 2017}

\section{Published online: 23 November 2017}

\section{References}

1. Morrone JJ. Cladistic biogeography of the neotropical region: identifying the main events in the diversification of the terrestrial biota. Cladistics. 2014 30:202-14.

2. Vermeij GJ. An agenda for invasion biology. Biol Conserv. 1996;78:3-9.

3. Webb SD. The great American biotic interchange: patterns and processes. Ann Missouri Bot Gard. 2006;93(2):245-57.

4. Weir JT, Bermingham E, Schluter D. The great American biotic interchange in birds. Proc Natl Acad Sci. 2009;106(51):21737-42

5. Woodburne MO. The great American biotic interchange: dispersals, tectonics, climate, sea level and holding pens. J Mamm Evol. 2010; 17:245-64.

6. Cody $\mathrm{S}$, et al. The great American biotic interchange revisited. Ecography. 2010;33:326-32

7. Constantino R. On-line termite database. http://164.41.140.9/catal/. Accessed 20 Nov 2017.

8. Mckern JA, et al. Phylogeography of termites (Isoptera) from Oregon and Washington. Sociobiology. 2007;50(2):607-22.

9. Tripodi AD, et al. Phylogeography of Reticulitermes termites (Isoptera: Rhinotermitidae) in California inferred from mitochondrial DNA sequences. Ann Entomol Soc Am. 2006:99(4):697-706.

10. Szalanski AL, et al. Molecular phylogeography of Reticulitermes (Isoptera: Rhinotermitidae) termites from Florida. Sociobiology. 2008:52(3):619-32.

11. Austin JW, et al. Molecular phylogeography of the subterranean termite Reticulitermes tibialis (Isoptera: Rhinotermitidae). J Agr Urban Entomol. 2008; 25(2):63-79.

12. Kutnik M. Phylogeography of two European Reticulitermes (Isoptera) species: the Iberian refugium. Mol Ecol. 2004;13(10):3099-113.

13. Lefebvre T, et al. From speciation to introgressive hybridization: the phylogeographic structure of an island subspecies of termite, Reticulitermes lucifugus corsicus. BMC Evol Biol. 2008:8:38.

14. Lefebvre T, et al. Subterranean termite phylogeography reveals multiple postglacial colonization events in southwestern Europe. Ecol Evol. 2016; 6(16):5987-6004

15. Park YC, et al. Intraspecific molecular phylogeny, genetic variation and phylogeography of Reticulitermes speratus (Isoptera: Rhinotermitidae). Mol Cells. 2006;21(1):89-103.

16. Li HF. Phylogeography of Coptotermes gestroi and Coptotermes formosanus (Isoptera: Rhinotermitidae) in Taiwan. Ann Entomol Soc Am. 2009;102(4):684-93.

17. Ozeki M, et al. Phylogeography of an Australian termite, Amitermes laurensis (Isoptera, Termitidae), with special reference to the variety of mound shapes. Mol Phylogenet Evol. 2007;42(1):236-47.

18. Constantino R. The pest termites of South America: taxonomy, distribution and status. J Appl Entomol. 2002;126(7-8):355-65.

19. Boulogne I, et al. Ecology of termites from the genus Nasutitermes (Termitidae: Nasutitermitinae) and potential for science-based development of sustainable pest management programs. J Pest Sci 2016;90:1-19.
20. Adams ES, Atkinson L, Bulmer MS. Relatedness, recognition errors, and colony fusion in the termite Nasutitermes corniger. Behav Ecol Sociobiol. 2007;61(8):1195-201.

21. Atkinson L, Teschendorf G, Adams ES. Lack of evidence for nepotism by workers tending queens of the polygynous termite Nasutitermes corniger. Behav Ecol Sociobiol. 2008;62(5):805-12.

22. Scheffrahn $\mathrm{RH}$, et al. Synonymy of neotropical arboreal termites Nasutitermes corniger and N. costalis (Isoptera: Termitidae: Nasutitermitinae), with evidence from morphology, genetics, and biogeography. Ann Entomol Soc Am. 2005a;98(3):273-81.

23. Scheffrahn $\mathrm{RH}$, et al. Synonymy of two arboreal termites (Isoptera: Termitidae: Nasutitermitinae): Nasutitermes corniger from the neotropics and N. polygynus from new Guinea. Fla Entomol. 2005b;88(1):28-33.

24. Avise JC, et al. Intraspecific phylogeography: the mitochondrial DNA bridge between population genetics and systematics. Annu Rev Ecol Evol Syst. 1987; 18:489-522.

25. Liu H, Beckenbach AT. Evolution of the mitochondrial cytochrome oxidase I gene among 10 orders of insects. Mol Phylogenet Evol. 1992;1(1):41-52.

26. Kambhampati SA. Phylogeny of cockroaches and related insects based on DNA sequence of mitochondrial ribosomal RNA genes. Proc Natl Acad Sci U S A. 1995;92:2017-20.

27. Xiong B, Kocher TD. Comparison of mitochondrial DNA sequences of seven morphospecies of black flies (Diptera: Simuliidae). Genome. 1991;34:306-11.

28. Legendre F, et al. The phylogeny of termites (Dictyoptera: Isoptera) based on mitochondrial and nuclear markers: implications for the evolution of the worker and pseudergate castes, and foraging behaviors. Mol Phylogenet Evol. 2008;48:615-27.

29. Hall TA. BioEdit: a user-friendly biological sequence alignment editor and analysis program for windows 95/98/NT. Nucleic Acids Symp Ser. 1999;41:95-8.

30. Librado P, Rozas J. DnaSP v5: a software for comprehensive analysis of DNA polymorphism data. Bioinformatics. 2009;25:1451-2.

31. Tamura K, et al. Mega 6: molecular evolutionary genetics analysis version 6 . 0. Mol Biol Evol. 2013;30:2725-9.

32. Fu Y. Statistical tests of neutrality of mutations against population growth, hitchhiking and background selection. Genetics. 1997;147(2):915-25.

33. Tajima F. Statistical method for testing the neutral mutation hypothesis by DNA polymorphism. Genetics. 1989;123(3):585-95.

34. Rogers AR, Harpending $H$. Population growth makes waves in the distribution of pairwise genetic differences. Mol Biol Evol. 1992;9(3):552-69.

35. Mousset S, Derome N, Veuille MA. Test of neutrality and constant population size based on the mismatch distribution. Mol Biol Evol. 2004 21(4):724-31.

36. Lopes IF. Variabilidade genética em populações de Jabiru mycteria (Lichtenstein, 1819) e Mycteria americana (Linneaus, 1758) (Aves Ciconiidae) fluxo gênico e filogeografia. In: Repositório Institucional UFSCar. 2006. https://repositorio.ufscar.br/bitstream/handle/ufscar/5362/TeselFL. pdf?sequence=1\&isAllowed=y. Accessed 20 Nov 2017.

37. Aoki K, Kato M, Murakami N. Glacial bottleneck and postglacial recolonization of a seed parasitic weevil, Curculio hilgendorfi, inferred from mitochondrial DNA variation. Mol Ecol. 2008;17(14):3276-89.

38. Clement M, Posada D, Crandall KA. TCS: a computer program to estimate gene genealogies. Mol Ecol. 2000;9:1657-9.

39. Templeton AR. Nested clade analyses of phylogeographic data: testing hypothese about gene flow and population history. Mol Ecol. 1998;7:381-97.

40. Posada D, Crandall KA, Templeton AR. GeoDis: a program for the cladistics nested analysis of the geographical distribution of genetic haplotypes. Mol Ecol. 2000:9:487-8.

41. Templeton AR. Statistical phylogeography: methods of evaluating and minimizing inference errors. Mol Ecol. 2004;13:789-809.

42. Miller MM. Alleles in space: computer software for the joint analysis of interindividual spatial and genetic information. J Hered. 2005:96:722-4.

43. Excoffier L, Laval G, Schneider S. Arlequin v.3.0: an integrated software package for population genetics data analysis. Evol Bioinforma Online. 2005;1:47-50.

44. Drummond AJ, et al. Bayesian phylogenetics with BEAUti and the BEAST 1.7 Mol Biol Evol. 2012;29:1969-73.

45. Ware JL, Grimaldi DA, Engel MS. The effects of fossil placement and calibration on divergence times and rates: an example from the termites (Insecta: Isoptera). Arthropod Struct Dev. 2010;39:204-19.

46. Bourguignon $\mathrm{T}$, et al. The evolutionary history of termites as inferred from 66 mitochondrial genomes. Mol Biol Evol. 2015;32(2):406-21. 
47. Thorne BL, Grimaldi DA, Krishna K. Early fossil history of the termites. In: Abe T, Bignell DE, Higashi M, editors. Termites: evolution, sociality, symbioses, ecology. Dordrecht: Kluwer Academic Publishers; 2000. p. 77-93.

48. Hasegawa M, Kishino H, Yano T. Dating of the human-ape splitting by a molecular clock of mitochondrial DNA. J Mol Evol. 1985;22(2):160-74.

49. Darriba $\mathrm{D}$, et al. JModel test 2: more models, new heuristics and parallel computing. Nat Methods. 2012;9:772.

50. Watterson GA, Guess HA. Is the most frequent allele the oldest? Theor Popul Biol. 1977;11(2):141-60.

51. Crandall KA, Templeton AR. Empirical tests of some predictions from coalescent theory with applications to intraspecific phylogeny reconstruction. Genetics. 1993;134(3):959-69.

52. Castelloe J, Templeton AR. Root probabilities for intraspecific gene trees under neutral coalescent theory. Mol Phylogenet Evol. 1994;3(2):102-13.

53. Emerson BC, Paradis E, Thébaud C. Revealing the demographic histories of species using DNA sequences. Trends Ecol Evol. 2001;16(12):707-16.

54. Michelsen Y. Revision of the aberrant new world genus Coenosopsia (Diptera: Anthomyiidae), with a discussion of anthomyiid relationships. Syst Entomol. 1991;16:85-104.

55. FCV Z. In: CJB C, EAB A, editors. Evolução da biotea da diagonal de formações abertas secas da América do Sul. São Paulo: Biogeografia da América do Sul: padrões \& processos; 2010. p. 198-220.

56. Croizat L. Vicariance/vicariism, panbiogeography, "vicariance biogeography", etc.: a clarification. Syst Zool. 1982;31:291-304.

57. Morley RJ. Origin and evolution of tropical rain forests. Chichester: John Wiley \& Sons; 2000.

58. Cancello EM, et al. Latitudinal variation in termite species richness and abundance along the Brazilian Atlantic Forest hotspot. Biotropica. 2014; 46(4):441-50.

59. DaSilva MB, Pinto-da-Rocha R. In: CJB C, EAB A, editors. História biogeográfica da mata atlântica: opiliões (Arachnida) como modelo para sua inferência. São Paulo: Biogeografia da América do Sul: padrões \& processos; 2010. p. 221-38.

\section{Submit your next manuscript to BioMed Central and we will help you at every step:}

- We accept pre-submission inquiries

- Our selector tool helps you to find the most relevant journal

- We provide round the clock customer support

- Convenient online submission

- Thorough peer review

- Inclusion in PubMed and all major indexing services

- Maximum visibility for your research

Submit your manuscript at www.biomedcentral.com/submit 